\title{
Calcium Phosphate Mineralization on Calcium Carbonate Particle Incorporated Silk-Fibroin Composites
}

\author{
Derya Kapusuz $^{*}$, Batur Ercan ${ }^{2,3}$ \\ ${ }^{1}$ Department of Metallurgical and Materials Engineering, Gaziantep University, Sehitkamil, Gaziantep, Turkey \\ ${ }^{2}$ Department of Metallurgical and Materials Engineering, ${ }^{3}$ Biomedical Engineering Program, Middle East Technical \\ University, Çankaya, Ankara, Turkey \\ *dkapusuz@gantep.edu.tr
}

Received: 03 June 2019

Accepted: 09 September 2019

DOI: $10.18466 /$ cbayarfbe. 573625

\begin{abstract}
In this study, three anhydrous forms of calcium carbonate, namely vaterite, aragonite and calcite, with distinct morphologies were incorporated inside silk-fibroin to fabricate composite scaffolds for tissue engineering applications. To assess calcium phosphate mineralization, composite scaffolds were treated with simulated body fluid up to one month. It was observed that composite scaffolds having different calcium carbonate polymorphs expressed different mineralization. Incorporating $25 \mathrm{wt}$ \% of vaterite polymorph, which was the least stable form of calcium carbonate under aqueous conditions, induced the highest calcium phosphate mineralization in silk-fibroin while calcium carbonate-free silk-fibroin scaffolds expressed no calcium phosphate deposition. Results highlighted the importance of calcium carbonate particles in enhancing the bioactivity of silk-fibroin based composite scaffolds.
\end{abstract}

Keywords: Silk-fibroin, $\mathrm{CaCO}_{3}$, composite, biomineralization, apatite.

\section{Introduction}

The fibroin core of silk - silk-fibroin (SF) - which is encapsulated inside a sericin outer lining, is a protein based fibrous biopolymer. Owing to its biocompatible nature, its use in various biomedical applications is investigated, i.e. sutures, wound dressings, vascular grafts, cartilage and bone regeneration agents and etc. [1]. Having this said, there are inherent problems associated with the use of SF as a biomaterial. Firstly, $\mathrm{SF}$ is not an osteoconductive (permits bone growth) material. It does not stimulate cellular functions of the juxtaposed tissues. Secondly, mechanical properties of $\mathrm{SF}$ are not suited for hard tissues. If SF was to be widely used in clinics as a biomaterial, its bioactivity and mechanical properties need to be remedied.

Combining two or more biocompatible materials to match the requirements of a specific application is a promising approach in biomedical research. In fact, composite forming strategy via incorporation of secondary phase particles provides remarkable advantages for SF based biomaterials so that the mechanical strength and bioactivity of SF could be improved simultaneously. For instance, Wang et al. dispersed graphene oxide (GO) sheets via ultrasonication to prepare GO/SF composites by solvent evaporation [2].

GO layers were found to improve thermal stability and mechanical strength simultaneously at low concentrations. Multiwalled carbon nanotubes (MWCNT) could also be incorporated into SF [3]. When the amount of MWCNT's increased up to $1 \mathrm{wt}$. $\%$, the beta $(\beta)$ sheet content, which was responsible for mechanical strength of the SF, increased from $35 \%$ to $49.4 \%$ with a corresponding 4.4-fold increase in the elastic modulus. In a recent study, up to $20 \% \mathrm{TiO}_{2}$ particles were incorporated in SF, which increased compressive strength for $15 \%$ [4]. Further incorporation of $\mathrm{TiO}_{2}$ particles led to agglomeration and failed to disperse homogeneously in the SF matrix and thus strength did not increase any more. When samples were soaked in simulated body fluid (SBF), spherical apatite crystals formed on composite scaffold surfaces up to 21 days.

Apatite is a family of calcium phosphate $(\mathrm{CaP})$ minerals with $\mathrm{Ca} / \mathrm{P}$ atomic ratio between $1.5-1.67$ and apatite constitutes the major inorganic part of the bone [5]. Owing to its osteoinductive potential and bioactive nature, recently it became a significantly promising candidate to reinforce SF [6]. In this regard, synthetic $\mathrm{CaP}$ minerals have been utilized to improve bone cell functions on SF scaffolds [7, 8]. Recently, well-known apatite phase, hydroxyapatite (HA; $\mathrm{Ca} / \mathrm{P}: 1.67)$ was used to reinforce SF. But it was not possible to disperse HA particles homogeneously in aqueous media and this led to agglomeration upon incorporation into SF at high concentrations [9]. To inhibit agglomeration of secondary phase particles and enhance SF biocompatibility, it was recently suggested that SF 
could be utilized as a template for the formation of biological apatites [10]. Specifically, the amorphous links in SF $\beta$-sheets could act as nucleation sites for HA crystals due to mimicking the anionic structure of noncollagenous proteins present in bone tissue [11].

To further stimulate formation of uniformly distributed apatite minerals within SF matrix, dispersing calcium sources that can form apatite crystals in-situ in SF would be a promising approach for bone regeneration. Among various calcium sources that can form apatite crystals in-situ, calcium carbonate $\left(\mathrm{CaCO}_{3}\right)$ polymorphs drew significant attention owing to their dissolution capability in aqueous media. In fact, $\mathrm{CaCO}_{3}$ has three anhydrous polymorphs: i) vaterite, ii) aragonite and iii) calcite.

Vaterite is the least stable and thus most soluble form of $\mathrm{CaCO}_{3}$. When placed in simulated body fluid (SBF) or phosphate buffer solution (PBS), vaterite particles transformed to hydroxyl carbonate apatite [12]. Thus, vaterite has a clear advantage to stimulate bioactivity relative to other synthetic materials and this was specifically important in orthopedics since $\mathrm{CaP}$ is present in natural bone [13]. For the case of aragonite, researchers indicated that aragonite particles could dissolve and be replaced with bone tissue [14]. Aragonite particles could be utilized as dual substrates for bone regeneration and drug release and calcite based scaffolds promote adhesion and proliferation of bone cells in vitro [15].

In this study, different anhydrous polymorphs of $\mathrm{CaCO}_{3}$ having distinct morphologies were incorporated into $\mathrm{SF}$ to fabricate $\mathrm{SF} / \mathrm{CaCO}_{3}$ composites. To assess $\mathrm{CaP}$ mineralization on scaffolds, samples interacted with SBF up to 1 month. This was the first study in literature to focus on the bioactivity enhancement of SF by $\mathrm{CaCO}_{3}$ incorporation and to investigate the fabrication and $\mathrm{CaP}$ mineral formation on $\mathrm{SF} / \mathrm{CaCO}_{3}$ composites as per changes in the polymorph of $\mathrm{CaCO}_{3}$.

\section{Materials and Methods}

All chemicals were purchased as analytical grade and used without further purification. Calcium acetate $\left(\mathrm{C}_{4} \mathrm{H}_{6} \mathrm{O}_{4} \mathrm{Ca}\right)$, sodium bicarbonate $\left(\mathrm{NaHCO}_{3}\right)$, ethylene glycol (EG; $\mathrm{C}_{2} \mathrm{H}_{6} \mathrm{O}_{2}$ ) and sodium hydroxide $(\mathrm{NaOH})$ were purchased from Sigma-Aldrich and water used in these experiments was purified using Millipore Milli-Q purification system.

\subsection{Synthesis of $\mathrm{CaCO}_{3}$ Particles}

To synthesize $\mathrm{CaCO}_{3}$ particles, $4 \mathrm{~mL}$ of $1 \mathrm{M} \mathrm{NaHCO}_{3}$ and $0.3 \mathrm{M} \mathrm{C}_{4} \mathrm{H}_{6} \mathrm{O}_{4} \mathrm{Ca}$ solutions were prepared separately and their $\mathrm{pH}$ values were adjusted to 12 . Afterwards, $\mathrm{NaHCO}_{3}$ solution was dispersed in $10,20,40$ or $50 \mathrm{~mL}$ EG to investigate the effect of EG concentration on $\mathrm{CaCO}_{3}$ crystallization. Subsequently, $\mathrm{C}_{4} \mathrm{H}_{6} \mathrm{O}_{4} \mathrm{Ca}$ solution was poured into the $\mathrm{EG} / \mathrm{NaHCO}_{3}$ solution, followed by stirring for $30 \mathrm{~min}$. Upon precipitation of $\mathrm{CaCO}_{3}$ particles, the solution was centrifuged with water and ethanol three times, respectively, to rinse the particles. The resultant wet powders were dried at $50^{\circ} \mathrm{C}$ for 2 h. EG10, EG20, EG40 and EG50 referred to $\mathrm{CaCO}_{3}$ particles prepared using $\mathrm{NaHCO}_{3}$ solutions containing 10, 20, 40 and $50 \mathrm{~mL}$ EG, respectively.

\subsection{Production of $\mathrm{SF} / \mathrm{CaCO}_{3}$ Composites}

A modified version of Kaplan's protocol was used to prepare SF solutions [16]. SF was extracted from Bombyx Mori cocoons by boiling them in $0.02 \mathrm{M}$ $\mathrm{Na}_{2} \mathrm{CO}_{3}$ solution for $30 \mathrm{~min}$. Afterwards, fibroin was dissolved in $12 \mathrm{M} \mathrm{LiBr}$ solution and dialyzed against distilled water for 2 days. Dialyzed fibroin was centrifuged for $30 \mathrm{~min}$, frozen in $-20{ }^{\circ} \mathrm{C}$ for $24 \mathrm{~h}$ and lyophilized using Christ Alpha 2-4 LD plus freeze dryer to remove water. The lyophilized SF was stored at room temperature. From lyophilized SF, two aqueous SF solutions containing $0.03 \mathrm{~g} / \mathrm{mL}(\mathrm{SF} 3)$ and $0.06 \mathrm{~g} / \mathrm{mL}$ (SF6) fibroin were prepared. Next, $0.025 \mathrm{~g}$ of EG10, EG40 and EG50 particles were dispersed manually in $2.5 \mathrm{~mL}$ of each SF solution, followed by lyophilizing for $24 \mathrm{~h}$. In this research, six different $\mathrm{SF} / \mathrm{CaCO}_{3}$ composite samples were prepared, as identified in Table 1. $\mathrm{CaCO}_{3}$-free $\mathrm{SF} 3$ and SF6 were used as control samples.

Table 1. SF/CaCO 3 composite formulations.

\begin{tabular}{lllc}
\hline Composite & $\begin{array}{l}\text { SF } \\
\text { Concentration, } \\
\text { g/mL }\end{array}$ & $\begin{array}{l}\text { Total } \\
\text { Volume, } \\
\text { mL }\end{array}$ & $\begin{array}{l}\mathrm{CaCO}_{3} \\
\text { content, } \\
\text { wt. \% }\end{array}$ \\
\hline SF6-EG10 & & & \\
SF6-EG40 & 0.06 & 2.5 & 15 \\
SF6-EG50 & & & \\
\hline SF3-EG10 & & 2.5 & 25 \\
SF3-EG40 & 0.03 & & \\
SF3-EG50 & & & \\
\hline
\end{tabular}

\subsection{Characterization}

For the structural characterization of $\mathrm{CaCO}_{3}$ particles and $\mathrm{SF} / \mathrm{CaCO}_{3}$ composites, X-ray diffraction (XRD), scanning electron microscopy (SEM) and Fouriertransformed infrared spectroscopy (FTIR) analyses were performed. For polymorphic analysis, Rigaku D-Max2200 diffractometer with $\mathrm{Cu} \mathrm{K}$-alpha radiation was used to scan the samples at $20-60^{\circ}$ diffraction angles at a rate of $2 \% \mathrm{~min}$.

For morphological analysis, Nova Nano SEM 430 was used at $20 \mathrm{kV}$ accelerating voltage. Prior to imaging, samples were coated with a thin layer of gold using Quorum SC7640 high-resolution sputter coater. For chemical analysis, FTIR scans were performed to analyze the $\mathrm{CaCO}_{3}$ polymorphs chemically. Perkin Elmer Spectrum 100 spectrometer was used in attenuated total reflection (ATR) mode and each sample was scanned in $4000-400 \mathrm{~cm}^{-1}$ range with a 
wavenumber resolution of $4 \mathrm{~cm}^{-1}$. The background spectra were subtracted from the obtained reflectance.

\subsection{CaP Mineralization}

SF, SF3-EG10, SF3-EG40, SF3-EG50, SF6-EG10, SF6EG40 and SF6-EG50 were immersed in simulated body fluid (SBF) to assess calcium phosphate mineralization. For the preparation of 1xSBF, Kokubo's protocol was used [17]. Briefly, $\mathrm{NaCl}$ (8.035 g/L), $\mathrm{NaHCO}_{3}(0.355$ $\mathrm{g} / \mathrm{L}), \quad \mathrm{KCl}(0.225 \mathrm{~g} / \mathrm{L}), \mathrm{K}_{2} \mathrm{HPO}_{4} .3 \mathrm{H}_{2} \mathrm{O}(0.231 \mathrm{~g} / \mathrm{L})$, $\mathrm{MgCl}_{2} \cdot 6 \mathrm{H}_{2} \mathrm{O}(0.311 \mathrm{~g} / \mathrm{L}), 1 \mathrm{M} \mathrm{HCl}(39 \mathrm{ml}), \mathrm{CaCl}_{2}$ $(0.292 \mathrm{~g} / \mathrm{L})$ and $\mathrm{Na}_{2} \mathrm{SO}_{4}(0.072 \mathrm{~g} / \mathrm{L})$ were dissolved in distilled water, respectively, followed by buffering with Tris $(6.118 \mathrm{~g} / \mathrm{L})$ and $1 \mathrm{M} \mathrm{HCl}$. Samples were kept in $1 \mathrm{xSBF}$ at $37^{\circ} \mathrm{C}$ for one month. Calcium and phosphate minerals were detected with energy dispersive spectroscopy (EDS) using an EDAX-AMETEK detector attached to SEM.

\section{Results and Discussion}

\subsection{Synthesis of $\mathrm{CaCO}_{3}$ particles}

SEM images, XRD and FTIR spectra of $\mathrm{CaCO}_{3}$ particles were displayed in Figure 1. SEM images (Figure 1a) revealed morphology of the particles. EG-50 samples exhibited ellipsoidal vaterite morphology. As the EG content of the precursor solutions decreased, morphology of the samples was altered. Unlike EG50, EG40 particles were spherical and upon further decreasing the EG content of the precursor to $20 \mathrm{~mL}$, aragonite, which had the appearance of needle-like bundles, began to crystallize and were less apparent at $10 \mathrm{~mL}$ EG concentration. SEM micrographs showed EG10 particles also to have rhombohedral (cubic) morphology, which was the hallmark of calcite. XRD spectra confirmed the observations obtained via SEM and identified polymorphs present in the powders (Figure 1b). In the XRD spectra, all peaks were ascribed to the anhydrous forms of $\mathrm{CaCO}_{3}$; vaterite (V; ICDD: 033-0268), aragonite (A; ICDD: 41-1475) and calcite (C; 005-0586). EG50 particles were phase-pure vaterite, while EG40 had some calcite polymorph. Only peaks belonging to vaterite appeared for EG50 samples, while calcite and vaterite peaks were present in the XRD spectrum of EG40 samples. For the case of EG20 and EG10 samples, XRD spectra had peaks belonging to all three anhydrous polymorphs of $\mathrm{CaCO}_{3}$; vaterite, calcite and aragonite.

These results were in accord with FTIR spectra of $\mathrm{CaCO}_{3}$ particles (Figure 1c) where characteristic absorption bands corresponding to different vibrational modes of $\mathrm{CO}_{3}{ }^{2-}$ were investigated. All samples expressed absorption bands of vaterite at $877 \mathrm{~cm}^{-1}(\mathrm{v} 2)$, $849 \mathrm{~cm}^{-1}$ (v2), $744 \mathrm{~cm}^{-1}$ (v4). Calcite absorption bands at $877 \mathrm{~cm}^{-1}(\mathrm{v} 2), 712 \mathrm{~cm}^{-1}$ (v4) were only present for EG40, EG20 and EG10 samples, while presence of aragonite polymorph was confirmed by absorption bands at $854 \mathrm{~cm}^{-1}$ (v2) and $700 \mathrm{~cm}^{-1}$ (v4) for EG20 and EG10 samples [18].
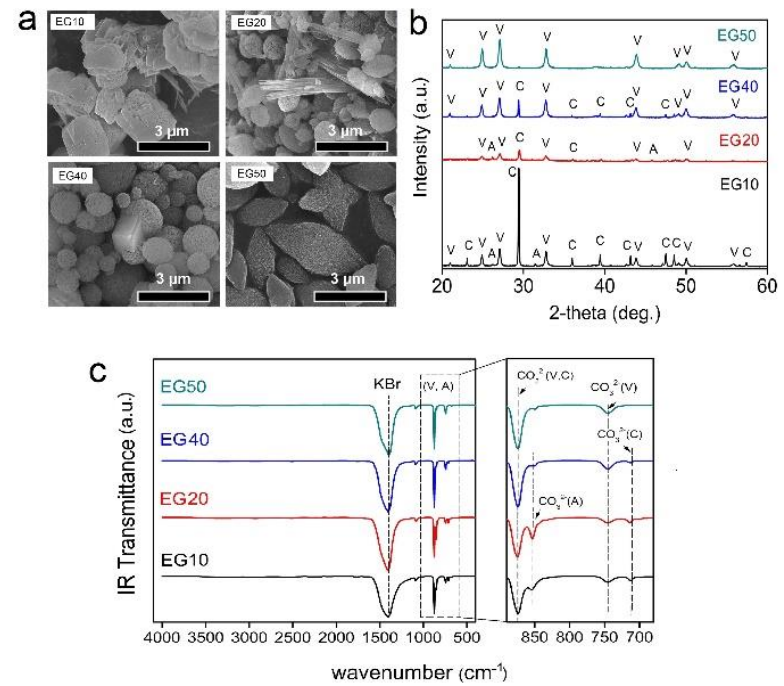

Figure 1. a) SEM images, b) XRD spectra and c) FTIR spectra of $\mathrm{CaCO}_{3}$ particles precipitated using 10, 20, 40 and $50 \mathrm{~mL}$ EG. "V", "A" and "C" denote peaks corresponding to vaterite, aragonite and calcite polymorphs, respectively.

\subsection{Characterization and bioactivity of $\mathrm{SF} / \mathrm{CaCO}_{3}$ composites}

In this research, three formulations of $\mathrm{CaCO}_{3}$ particles (EG10, EG40 and EG50), which contained three $\mathrm{CaCO}_{3}$ polymorphs (V, C and $\mathrm{A}$ ), were incorporated in SF. EG10 particles which consisted of calcite, vaterite and aragonite, EG40 particles which consisted mainly of a mixture of spherical vaterite and calcite, and EG50 particles which were almost-pure ellipsoidal vaterite were used to reinforce SF scaffolds at 15 and $25 \mathrm{wt} \%$. Lyophilized $\mathrm{SF} / \mathrm{CaCO}_{3}$ composites are displayed in Figure 2a. Results confirmed porous nature of the SF scaffolds where formation of pores upon lyophilization was not affected by the type of $\mathrm{CaCO}_{3}$ particles incorporated into the scaffolds [19]. Images revealed that $\mathrm{CaCO}_{3}$ particles could be dispersed as a secondary phase within SF scaffolds. $\mathrm{SF} 6 / \mathrm{CaCO}_{3}$ composites (SF6-EGX) had $15 \% \mathrm{CaCO}_{3}$ particles and had smooth surfaces, yet as $\mathrm{CaCO}_{3}$ content increased to $25 \%$ (SF3EGX), $\mathrm{CaCO}_{3}$ particles were revealed on SF surfaces. $\mathrm{XRD}$ spectra of these composites were given in Figure $2 b$.

$\mathrm{CaCO}_{3}$-free $\mathrm{SF}$ has three characteristic peaks centered at $8.8^{\circ}, 20.4^{\circ}$ and $24^{\circ}[20]$. The spectra revealed tiny peaks at $21^{\circ}$ and $24^{\circ}$ for $\mathrm{CaCO}_{3}$-free $\mathrm{SF}$ and no crystalline peaks, but a large hump maximized around $24^{\circ}$ for the composites, indicating that the crystalline orientation between the beta sheets might have been distorted by the interaction with $\mathrm{CaCO}_{3}$ particles. XRD analysis confirmed successful incorporation of $\mathrm{CaCO}_{3}$ particles inside the SF matrix. Each intense peak observed in the XRD spectra of the composites could be ascribed to $\mathrm{CaCO}_{3}$ particles. Specifically, the most intense peaks of the $\mathrm{CaCO}_{3}$ polymorphs manifested themselves at the 
XRD spectra of their corresponding composite formulation. Peaks at $24.90^{\circ}, 27.04^{\circ}, 32.65^{\circ}, 43.90^{\circ}$ and $51.70^{\circ}$ were present for vaterite and at $29.45^{\circ}$ for calcite. Characteristic peaks of vaterite, aragonite and calcite were not evident in SF6 composites - except for the vaterite peak at $32.65^{\circ}$ - compared to those of SF3, most probably due to having lower particle concentration inside the composite scaffolds.

a
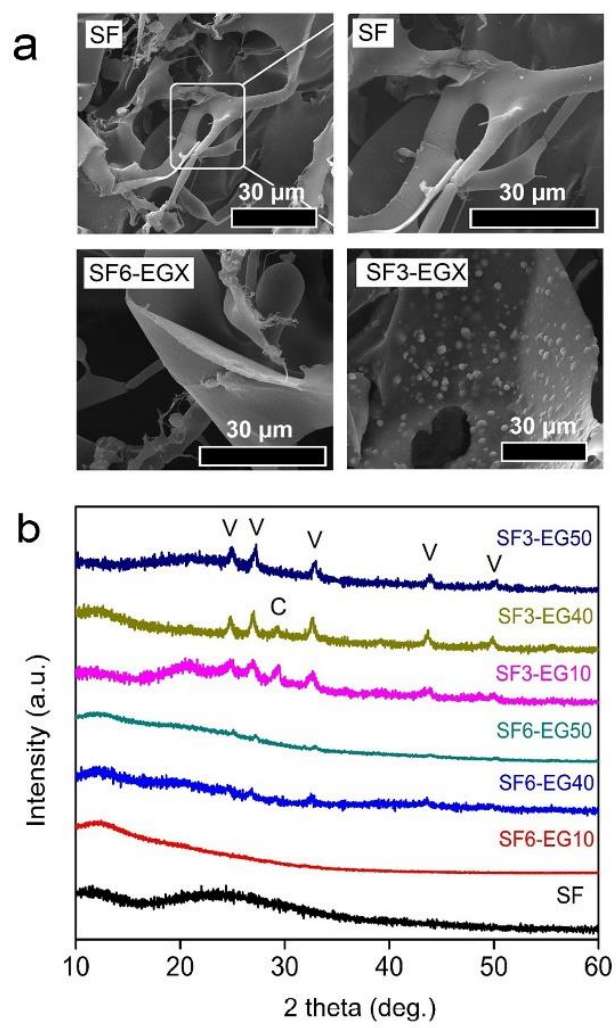

Figure 2. a) $\mathrm{SEM}$ images, b) $\mathrm{XRD}$ spectra of $\mathrm{SF} / \mathrm{CaCO}_{3}$ composites (X.10, 40 and 50) compared to $\mathrm{CaCO}_{3}$-free SF.

The $\mathrm{SF} / \mathrm{CaCO}_{3}$ composite scaffolds were soaked in $1 \mathrm{xSBF}$ for 1 month to assess their bioactivity in biological fluids. XRD scans taken after $1 \times$ SBF treatment are displayed in Figure 3 and compared with $\mathrm{CaCO}_{3}$-free SF. XRD spectra indicated that $\mathrm{CaCO}_{3}$-free SF surfaces preserved their amorphous-like structure; no significant CaP formation was observed. Similarly, 15 $\% \mathrm{CaCO}_{3}$ incorporation did not significantly induce $\mathrm{CaP}$ formation (SF6-EGX). However, increasing $\mathrm{CaCO}_{3}$ content to $25 \%$ (SF3-EGX) led to formation of apatite (A, JCPDS: 74-0566) after soaking in $1 \mathrm{xSBF}$ for one month. Apatite mineralization was confirmed also via SEM/EDS analysis. As shown in Figure $2 \mathrm{a}, \mathrm{CaCO}_{3}$-free scaffold surfaces were smooth before $1 \mathrm{xSBF}$ treatment. In Figure 4, the change in scaffold surfaces are shown after $1 \mathrm{xSBF}$ treatment for 1 month.

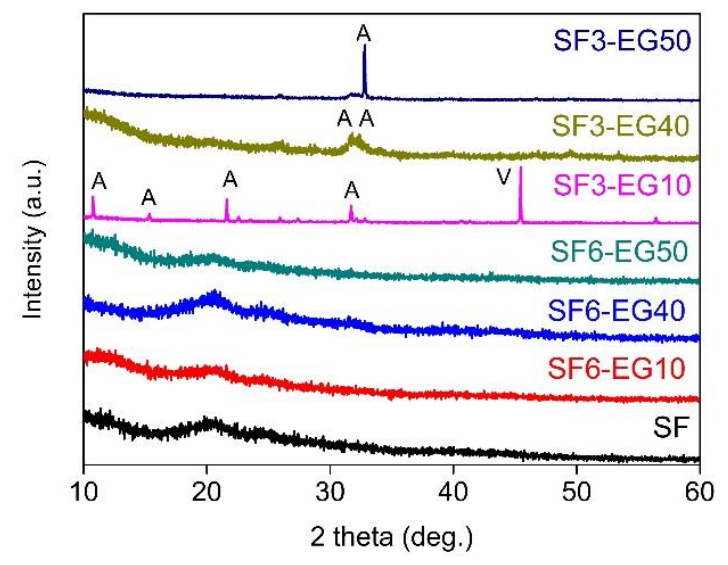

Figure 3. $\mathrm{XRD}$ spectra of $\mathrm{SF} / \mathrm{CaCO}_{3}$ composites (X.10, 40 and 50) compared to $\mathrm{CaCO}_{3}$-free $\mathrm{SF}$ after soaking in $1 \mathrm{xSBF}$ for 1 month.

SEM images of composite scaffold surfaces in Figure $4 \mathrm{a}$ to $4 \mathrm{f}$ showed that $\mathrm{SF}$ scaffolds stimulated minimal $\mathrm{CaP}$ mineralization and incorporation of $\mathrm{CaCO}_{3}$ significantly influenced mineralization. In Figure 4e, deposition of mineralized material on the smooth scaffold surface is most differentiable. A closer view of the $\mathrm{CaCO}_{3}$-free SF indicated mineral deposition on SF surface but not with a definite morphology (Figure 4g).

In the $\mathrm{SEM}$ micrographs of $\mathrm{SF} 3 / \mathrm{CaCO}_{3}$ composites treated with $\mathrm{SBF}$, crystallization of a new morphology (apatite) on each $\mathrm{SF} / \mathrm{CaCO}_{3}$ scaffold surfaces was evident (Figure 4h). EDS spectra exhibited calcium (Ca) and phosphorous (P) peaks for all the SF3 composite formulations, while $\mathrm{P}$ peak was not apparent for $\mathrm{CaCO}_{3}$ free SF (Table 2). SF6-EG10 and SF6-EG40 composites contained $\mathrm{Ca}$ and $\mathrm{P}$, however SF6-EG50 contained only $\mathrm{Ca}$. It can be speculated that $\mathrm{Ca}$ present in the $\mathrm{CaCO}_{3}$ partially contributed to the intensity of calcium peak obtained with the EDS analysis, yet phosphorous was only present at the $\mathrm{CaP}$ mineral forming on the scaffolds.

It could be speculated that these particles acted as templates for $\mathrm{CaP}$ nucleation and growth, and thus promoted mineralization via favoring an alternate route. The other elements observed in the EDS spectra ( $\mathrm{Na}$, $\mathrm{Mg}$ and $\mathrm{Cl}$ ) were most probably the ions adsorbed on the composite surfaces from the unreacted Kokubo's solution. 

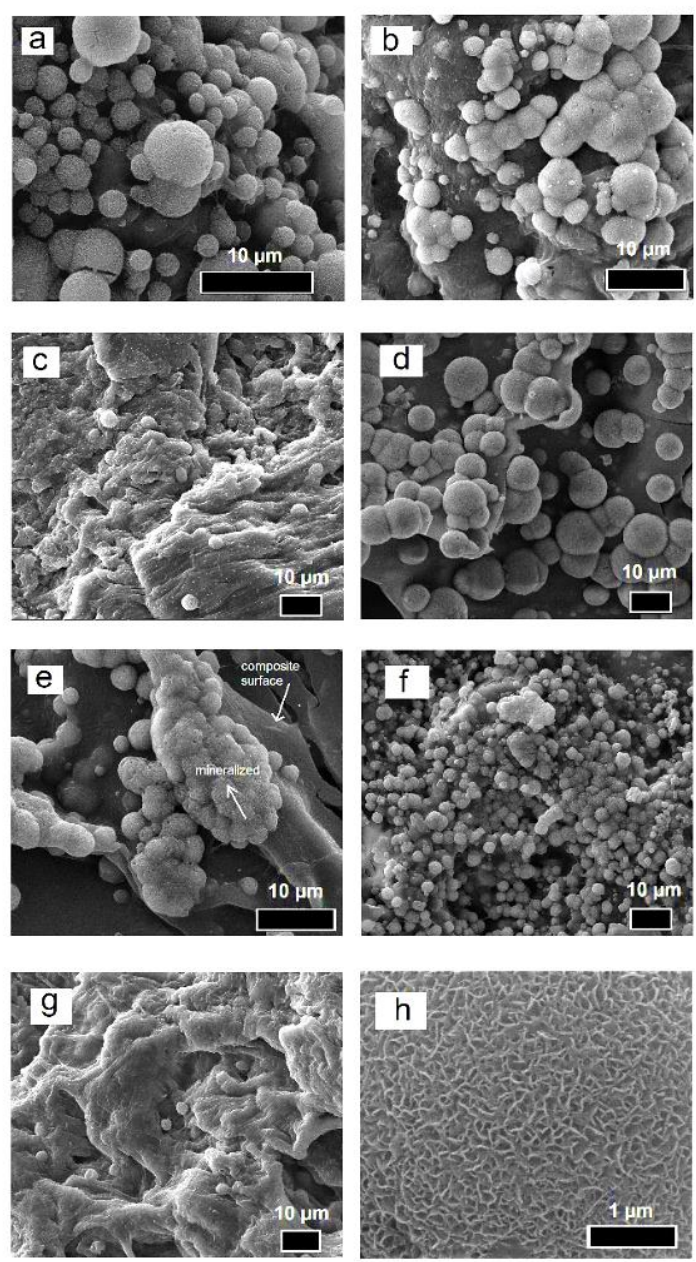

Figure 4. SEM images of a) SF6-EG10, b) SF6-EG40, c) SF6-EG50, d) SF3-EG10, e) SF3-EG40, f) SF3EG50, g) SF, h) detailed, representative image of mineralized apatite morphology on composites after immersion in $1 \mathrm{xSBF}$ for one month.

Table 2. Elemental compositions of the composite surfaces (average of 3 measurements) compared to SF after immersion in $1 \mathrm{xSBF}$ for one month.

\begin{tabular}{cccccl}
\hline Composite & Na & Mg & P & Cl & Ca \\
\hline SF6-EG10 & 4.81 & 4.48 & 35.68 & 6.62 & 48.41 \\
SF6-EG40 & 2.01 & - & 36.22 & 1.62 & 59.72 \\
SF6-EG50 & 29.42 & 5.44 & - & 57.34 & 4.11 \\
\hline SF3-EG10 & 7.04 & 2.39 & 31.52 & 8.66 & 50.39 \\
SF3-EG40 & 7.87 & - & 36.08 & 5.23 & 50.82 \\
SF3-EG50 & 3.19 & 2.89 & 38.39 & - & 54.74 \\
\hline SF & 24.79 & 12.66 & - & 33.69 & 19.32 \\
\hline
\end{tabular}

\section{Conclusions}

In this work, $\mathrm{CaCO}_{3}$ polymorphs were synthesized at different $\mathrm{EG}$ concentrations. Three $\mathrm{CaCO}_{3}$ formulations were chosen and $\mathrm{SF} / \mathrm{CaCO}_{3}$ scaffolds having different SF concentrations were prepared. Composites were characterized and tested for $\mathrm{CaP}$ mineralization upon interaction with $1 \mathrm{xSBF}$.

XRD, SEM and FTIR analyses of $\mathrm{CaCO}_{3}$ particles indicated that EG concentration directly influenced the polymorphic growth in solution. As the EG concentration decreased, phase-pure vaterite (EG50) transformed to vaterite-aragonite-calcite mixtures, in which almost phase-pure calcite could be obtained at the lowest EG concentration (EG10).

In the second part, $\mathrm{CaCO}_{3}$ incorporated $\mathrm{SF}$ scaffolds induced higher mineralization compared to SF-only scaffolds in $1 \times$ SBF at 1 month. By the XRD and SEMEDS analyses, it was shown that scaffolds containing $25 \% \mathrm{CaCO}_{3} \quad(\mathrm{EG} 50)$ displayed the highest $\mathrm{CaP}$ mineralization on the particle surfaces (SF3- EG50). Vaterite polymorph was the most effective $\mathrm{CaCO}_{3}$ form for the in-situ formation of $\mathrm{CaP}$ in $\mathrm{SF}$ matrix. This was a promising finding for the use of $\mathrm{SF} / \mathrm{CaCO}_{3}$ scaffolds in the biomaterials field and open the way for biological tests to assess the biocompatibility of these scaffolds. For future work, authors continue their studies to further assess the structural interaction at the $\mathrm{SF}-\mathrm{CaCO}_{3}$ interface and enhance the mechanical properties of the composites for use in orthopedic applications.

\section{Author's Contributions}

Derya Kapusuz: Contributed equally in drafting and writing the manuscript, performed the experiments, analyzed results.

Batur Ercan: Contributed equally in drafting and writing the manuscript, helped interpret the results.

\section{Ethics}

There are no ethical issues after the publication of this manuscript.

\section{Acknowledgement}

This work was supported by METU Research Funds Grant Number BAP-08-11-2017-019.

\section{References}

1. Murphy, A, R, Kaplan, D, L. 2010. Biomedical applications of chemically-modified silk fibroin. Journal of Materials Chemistry; 19(36): 6443-6450.

2. Wang, L, Chunxiang, L, Zhang, B, Zhao, B, Wu, F, Guan, S 2014. Fabrication and characterization of flexible silk fibroin films reinforced with graphene oxide for biomedical applications. RSC Advances; 4: 40312-40320.

3. Pan, C, Xie, Q, Hu, Z, Yang, M, Zhu, L. 2015. Mechanical and biological properties of silk fibroin/carbon nanotube nanocomposites films. Fibers and Polymers; 16(8): 1781-1787.

4. Johari, N, Hosseini, M, Taromi, N, Arasteh, S, Kazemnejad, S, Samadikuchaksaraci, A. 2018. Evaluation of bioactivity and biocompatibility of silk fibroin/ $/ \mathrm{TiO}_{2}$ nanocomposite. Journal of Medical and Biological Engineering; 38: 99-105.

5. Martin, R, B. 1999. Bone as a ceramic composite material. Materials Science Forum; 293: 5-16. 
6. Li, C, Jin, H, J, Botsaris, G, D, Kaplan, D, L. 2005. Silk apatite composites from electrospun fibers. Journal of Materials Research; 20(12): 3374e84.

7. Bhumiratana, S, Grayson, W, L, Castaneda, A, Rockwood, D, N, Gil, E, S, Kaplan, D, L, Novakovic, G. 2011. Nucleation and growth of mineralized bone matrix on silk-hydroxyapatite composite scaffolds. Biomaterials; 32: 2812-20.

8. Eliaz, N, Metoki, N. 2017. Calcium Phosphate Bioceramics: A Review of Their History, Structure, Properties, Coating Technologies and Biomedical Applications. Materials (Basel); 10: 334 .

9. Farokhi, M, Mottaghitalab, F, Samani, S, Shokrgozar, M. A, Kundu, S, C, Reis, R, L, Fatahi, Y, Kaplan, D, L. 2018. Silk fibroin/hydroxyapatite composites for bone tissue Engineering. Biotechnology Advances; 36(1): 68-91.

10. Wang, J, Yu, F, Qu, L, Meng, X, Wen, G. 2010. Study of synthesis of nano-hydroxyapatite using a silk fibroin template. Biomedical Materials; 5: 041002-041007.

11. Marelli, B, Ghezzi, C, E, Alessandrino, A, Barralet, J, E, Freddi, G, Nazhat, S, N. 2012. Silk fibroin derived polypeptide-induced biomineralization of collagen. Biomaterials; 33: 102-108.

12. Schröder, R, Besch, L, Pohlit, H, Panthöfer, M, Roth, W, Frey, H, Tremel, W, Unger, R, E. 2018. Particles of vaterite, a metastable $\mathrm{CaCO}_{3}$ polymorph, exhibit high biocompatiblity for human osteoblasts and endothelial cells and may serve as a biomaterial for rapid bone regeneration. Journal of Tissue Engineering and Regenerative Medicine; 12: 1754-1768.

13. Trushina, D, B, Bukreeva, T, V, Kovalchuk, M, V, Antipina, M, N. 2014. $\mathrm{CaCO}_{3}$ vaterite microparticles for biomedical and personal care applications. Materials Science and Engineering $C$; 45: 644-658

14. Akilal, N, Lemarie, F, Bercu, N, B, Sayen, S, Gangloff, S, C Khelfaoui, Y, Rammal, H, Kedjoudj, H. 2019. Cowries derived aragonite as raw Materials for bone regenerative medicine. Materials Science and Engineering C; 94, 894-900.

15. Wolsetsadik, A, D, Sharma, S, K, Khapli, S, Jagannathan, R 2017. Hierarchically porous calcium carbonate scaffolds for bone tissue engineering. ACS Biomaterials Science and Engineering; 3 : 2457-2469.

16. Rockwood, D, N, Preda, R, C, Yücel, T, Wang, X, Lovett, M, L, Kaplan, D, L. 2011. Materials fabrication from Bombyx mori silk fibroin, Nature Protocols; 6(10): 1612-1631.

17. Kokubo, T, Takadama, H. 2006. How useful is SBF in predicting in vivo bone bioactivity? Biomaterials; 27(15): 2907-2915.

18. Ševčík, R, Pérez-Estébanez, M, Viani, A, Šašek, P, Mácová, P. 2015. Characterization of vaterite synthesized at various temperatures and stirring velocities without use of additives. Powder Technology; 284: 265-271.

19. Lu, Y, Zhang, S, Liu, X, Ye, S, Zhou, X, Huang, Q, Ren, L. 2017. Silk/agarose scaffolds with tunable properties via SDS assisted rapid gelation. RSC Advances; 7: 21740-21748.

20. Asakura, T, Kuzuhara, A, Tabeta, R, Saito, H. 1985. Conformation Characterization of Bombyx mori silk fibroin in the solid state by high frequency $13 \mathrm{C}$ cross-polarization-magic Angle spinning NMR, X-ray diffraction, and infrared spectroscopy. Macromolecules; 18: 1841-1845. 